Melanie Y. Marino, MD

Antonio H. Chua, MD

Department of Otorhinolaryngology

Head and Neck Surgery

Jose R. Reyes Memorial Medical Center
Correspondence: Melanie Y. Marino, M.D.

Department of Otorhinolaryngology Head and Neck Surgery Jose R. Reyes Memorial Medical Center

Rizal Avenue, Sta. Cruz, Manila 1003

Telefax: (632) 7436921

Email:mimimarines@yahoo.com

Reprints will not be available from the author.

\title{
Congenital Saccular Cyst of the Larynx
}

Congenital saccular cysts of the larynx are a rare cause of airway obstruction in the neonatal population. Symptoms are non-specific and common to other causes of laryngeal obstruction. Prompt recognition and management is important because of the high mortality associated with undiagnosed conditions.

\section{CASE}

A 2-month-old female was seen at the Pediatric emergency room because of breathing difficulty. She had productive cough two days prior, accompanied by labored breathing, vomiting and poor appetite. She was admitted at the Pediatric ICU with a diagnosis of acute bronchiolitis. Attempting intubation, the pediatric resident noted a cystic mass partially obstructing the laryngeal inlet. The patient was successfully intubated on the third attempt. Review of history revealed stridor at birth, and she was referred to the ENT service for further management. Awake Flexible Laryngoscopy revealed a cystic mass obscuring most of the right vocal fold. The impression was an anterior saccular cyst.

The patient underwent microlarygoscopy. The cyst extended posterosuperiorly, resting over the false vocal fold (Figure 1). The presence of a saccular cyst was confirmed by needle aspiration of whitish gelatinous fluid, immediately collapsing the cyst wall (Figure 2). Excision was performed with dissection of the cyst to its base at the saccule orifice. The entire sac was excised with minimal bleeding. After excision, the endotracheal tube was reduced to the next smaller size. She was extubated on the third postoperative day and did not require re-intubation. The patient was kept on intravenous antibiotics and steroids until she was discharged on the sixth postoperative day without further airway symptoms.

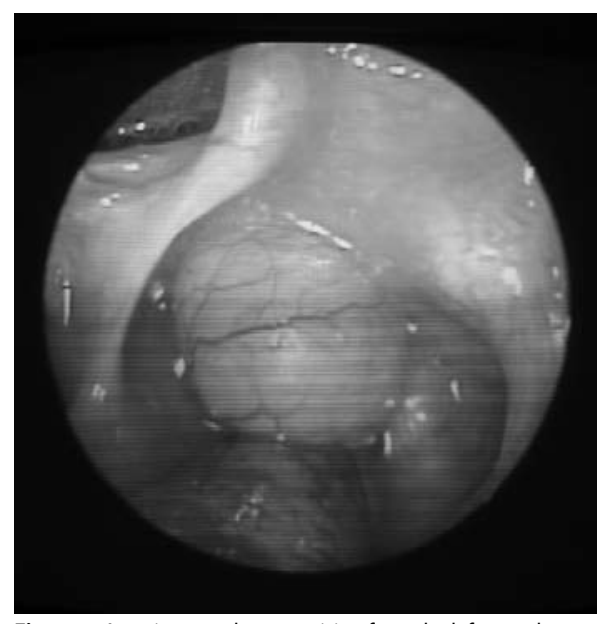

Figure 1. Anterior saccular cyst arising from the left saccule.

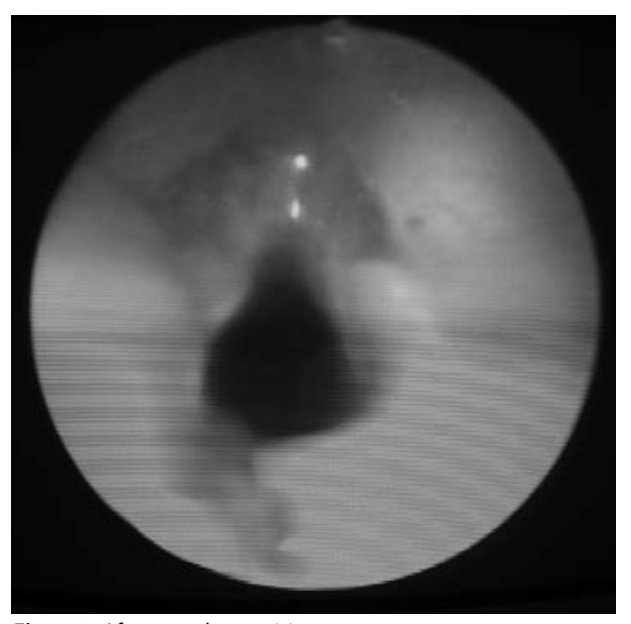

Figure 2. After complete excision 
FEATURED GRAND ROUNDS

Philippine Journal Of Otolaryngology-Head And Neck Surgery

VOL. 23 No. 1 JANUARY - JUNE 2008

PJOHLS

\section{DISCUSSION}

Congenital saccular cysts of the larynx are unusual lesions that commonly present with respiratory obstruction in infants and children. ${ }^{1}$ They are thought to arise in the saccule of the ventricle of the larynx. A laryngeal saccule is a small diverticulum arising out of the laryngeal ventricle. It extends upward between the false vocal fold, the base of the epiglottis, and the thyroid cartilage. It contains mucous glands and secretes mucus through an orifice in the anterior part of the roof of the ventricle.

A congenital saccular cyst is believed to form as a result of a developmental failure to maintain patency of the saccular orifice. It is similar to a laryngocele in that it represents an abnormal dilatation or herniation of the saccule, however it is distinct from a laryngocele in that there is no opening to the ventricle of the larynx, and it is filled with mucus. ${ }^{1}$ On the other hand, a laryngocele is defined as a dilatation or herniation of the laryngeal saccule, which is filled with air.

DeSanto, Devine, and Weiland ${ }^{2}$ classified all cystic laryngeal lesions into saccular, ductal, and thyroid cartilage foraminal cysts. They further classified saccular cysts into anterior and lateral saccular cysts. The anterior saccular cyst extends medially and posteriorly from the saccule and protrudes into the laryngeal lumen between the true and false vocal cords. The lateral saccular cyst typically extends posterosuperiorly into the false vocal cord and aryepiglottic fold. This is the larger of the two types and is the more common form encountered in infants. Large lateral saccular cysts can extend into the lateral vallecula or bulge the medial wall of the pyriform sinus. It can also herniate through the thyrohyoid membrane similar to a laryngocele and can appear in the neck.

Recently Forte, Fuoco, and James 3 proposed a new classification dividing laryngeal cysts into two types based on the extent of the cyst and on the embryologic tissue of origin. A cyst that is radiologically and clinically determined to be intralaryngeal and can be safely and completely excised endoscopically is classified as Type I. Those with extralaryngeal extension are classified as Type II, subclassified into Ila (endodermal elements only) and IIb (endodermal and mesodermal elements - laryngotracheal duplication or diverticulum).

Saccular cysts cause respiratory distress and inspiratory stridor most often at birth. The cry may be muffled, and dysphagia may occur. The diagnosis is suggested by a soft tissue lateral radiograph that shows a mucus-filled sac. ${ }^{1}$ This can be confirmed by fiberoptic laryngoscopy. The anterior saccular cyst is seen as a small round swelling protruding from the anterior ventricle and overhanging the anterior part of the ipsilateral vocal fold. The lateral saccular cyst appears as a smooth, mucosa-covered swelling of the false vocal fold and aryepiglottic fold. Both computed tomography and MRI may be helpful in delineating the exact location and extent of the mass. In our patient, the diagnosis was arrived at on the basis of clinical presentation and endoscopic findings.

A good airway must first be secured prior to definitive management. Fortunately, our patient was successfully intubated, negating the need for a tracheotomy. The classic treatment of the lateral saccular cyst has been endoscopic management. ${ }^{1}$ Needle aspiration through a direct laryngoscope has been suggested as the initial treatment but recurrence is the norm because of the difficulty in completely obliterating the cyst by this method. ${ }^{1}$ Endoscopic marsupialization with or without stripping of the cyst lining has been advocated. Abramson and Zielinski ${ }^{4}$ introduced the application of carbon dioxide laser to incise the cyst and vaporize its lining. Booth and Birck ${ }^{5}$ used cup forceps to unroof laryngoceles and saccular cysts in neonates, followed by a 3-day intubation. Holinger et al ${ }^{6}$ performed direct laryngoscopy and endoscopic removal with cup forceps. In this patient, we performed endoscopic excision using cup forceps, dissecting the cyst to its base at the orifice of the saccule before amputation. Intubation was maintained to protect the infant's airway and likewise act as a stent, similar to the technique described by Booth and Birck. ${ }^{5}$

Large saccular cysts occasionally require an external approach. A lateral cervical approach extending through the thyrohyoid membrane immediately above the alar of thyroid cartilage is the procedure of choice in such cases. ${ }^{2}$

\section{ACKNOWLEDGEMENT:}

We would like to extend our heartfelt thanks to Dr. Samantha S. Castañeda for reviewing the manuscript.

\section{REFERENCES:}

1. Cotton RT, Prescott CA. Congenital Anomalies of the Larynx. In: Cotton RT, Myer CM, editors. Practical Pediatric Otolaryngology. Philadelphia, PA: Lippincott-Raven; 1999. p. 508-509.

2. DeSanto LW, Devine KD, Weiland LH. Cysts of the larynx: Classification. Laryngoscope 1970:261267.

3. Forte V, Fuoco G, James A. A New Classification System for Congenital Laryngeal Cysts. Laryngoscope 2004;114:1123-1127.

4. Abramson AL,Zielinski B. Congenital saccular cysts of the newborn. Laryngoscope 1984;94:15801581.

5. Booth JB, Birck HG. Operative treatment and postoperative management of saccular cyst and laryngocele. Arch Otolaryngol Head Neck Surg 1981;107:500

6. Holinger PH, Holinger LD, Barnes DR, Smid LJ. Laryngocele and saccular cysts. Ann Otol 1978;87:675-685. 